\title{
The Importance of Eosinopenia for Predicting Treatment Response in Patients with Cholangitis
}

\author{
Cengiz Karacaer ${ }^{1}$, Ahmet Tarik Eminler², Bilal Toka², Mukaddes Tozlu², Erkan Parlak ${ }^{2}$ and Aydin Seref Koksal ${ }^{2}$ \\ ${ }^{1}$ Department of Internal Medicine, Sakarya University Research and Education Hospital, Sakarya, Turkey \\ ${ }^{2}$ Department of Gastroenterology, Sakarya University Research and Education Hospital, Sakarya, Turkey
}

\begin{abstract}
Objective: To compare recovery of eosinopenia, C-reactive protein (CRP) and procalcitonin levels in predicting the response to treatment in patients with cholangitis.

Study Design: Descriptive, analytical study.

Place and Duration of Study: Department of Gastroenterology, Sakarya Training and Research Hospital, Turkey between September 2018 and February 2019.

Methodology: Patients with cholangitis, who underwent endoscopic retrograde cholangiopancreatography (ERCP), were inducted. Those with choledocholic thiasis alone were considered controls. Eosinophil count above $100.5 \mathrm{cells} / \mu \mathrm{L}$ was the limit value accepted as improvement. ERCP repeat was decided according to eosinophil count below 100.5 and not clinically improving. Relationship between inflammatory markers such as CRP, procalcitonin and eosinopenia values in patients with stone-associated cholangitis was investigated.

Results: The cholangitis group was comprised of 62 patients [mean age $67 \pm 14.57$ years; $26(41.9 \%)$ female], while control group was comprised of 57 patients [mean age $57.4 \pm 18.10$ years; $39(68.4 \%)$ females, $p=0.004$ ]. At time of admission, median eosinophils was significantly lower in cholangitis group at $17.50[9.82-84] \times 10^{3} / \mu \mathrm{L}$ compared to control group at 168 [100.11-270] $\times 10^{3} / \mu \mathrm{L}(\mathrm{p}=0.001)$. ERCP were repeated on two patients as their clinical conditions and unremitting eosinophil counts worsened. Eosinophil and CRP markers and clinical improvement were observed after second ERCP procedure.

Conclusion: Eosinopenia may be used as inflammatory marker in evaluation of response to treatment and for predicting the need to repeat ERCP during clinical follow-up of patients who undergo cholangitis treatment.
\end{abstract}

Key Words: Cholangitis, C-reactive protein, Endoscopic retrograde cholangiopancreatography, Eosinopenia, Procalcitonin.

How to cite this article: Karacaer C, Eminler AT, Toka B, Tozlu M, Parlak E, Koksal AS. The Importance of Eosinopenia for Predicting Treatment Response in Patients with Cholangitis. J Coll Physicians Surg Pak 2020; 30(11):1143-1148.

\section{INTRODUCTION}

Acute cholangitis is a life-threatening condition that was first defined by Charcot in 1877. It is characterised by a fever, jaundice, and right upper quadrant abdominal pain and affects the biliary tract as a result of stasis and infection. ${ }^{1,2}$ Acute cholangitis is most frequently caused by biliary stones, benign strictures, and malignancy. ${ }^{3}$ Biliary drainage should be carried out with endoscopic retrograde cholangiopancreatography (ERCP) in the treatment of patients with acute cholangitis. In situations where drainage with ERCP is not technically appropriate, decompression of the biliary tract by means of percutaneous transhepatic cholangiography or a surgical operation may be required. ${ }^{4}$

Correspondence to: Dr. Cengiz Karacaer, Department of Internal Medicine, Sakarya University Research and Education Hospital, Sakarya, Turkey

E-mail: karacaerc@yahoo.com

Received: August 22, 2020; Revised: October 24, 2020;

Accepted: November 04, 2020

DOI: https://doi.org/10.29271/jcpsp.2020.11.1143
The most frequently measured laboratory inflammation parameters are the leukocyte count, $\mathrm{C}$-reactive protein (CRP) and procalcitonin (PCT). ${ }^{5}$ Leukocyte count may be affected by various inflammatory and physiological processes, such as infectious or traumatic stress. ${ }^{6}$ The half-life of the CRP is long, which may cause delays in choosing interventional procedures and modifying antibiotic therapy. ${ }^{7}$

Eosinopenia is induced by adrenal glucocorticoids and epinephrine and by the rapid sequestration of circulating eosinophils. ${ }^{8}$ Very few studies in the literature have focused on acute infection and eosinopenia., ${ }^{9,10}$ Measuring the eosinophil count does not increase costs as it is routinely measured within the complete blood count $(C B C)$ in clinical practices. ${ }^{11}$ The short half-life of eosinophils is another significantadvantage. ${ }^{12}$

The aim of this study was to investigate the value of eosinopenia in predicting the response to treatment in patients with cholangitis. 


\section{METHODOLOGY}

This study was conducted as a descriptive, analytical study with patients who had cholangitisand wereadmitted tothe Gastroenterology Department of Sakarya Training and Research Hospital between September 2018 and February 2019. The study protocol was approved by the Ethics Committee (Registration No: 16214662/050.01.04/7). Written informed consent was obtained from all patients or their legal representatives.

The control group was comprised of patients who underwent ERCP for asymptomatic choledocholithiasis only. Choledocholithiasis was diagnosed in the patients prior to the ERCP by means of transabdominal ultrasound and, when necessary, by magnetic retrograde cholangio pancreatography and/orendoscopic ultrasound. The exclusion criteria were diseases that may cause eosinophilia, such as parasitic diseases, allergy/atopy, allergic drug reactions (aspirin, penicillin, nitrofurantoin, sulfonamide, iodides), asthma, urticaria, eczema, allergic rhinitis, angioneurotic edema, reactive eosinophilia (T-cell lymphoma, B-cell lymphoma, acute lymphoblastic leukemia, eosinophilic leukemia), idiopathic hypereosinophilic syndrome, collagen vascular diseases (e.g., rheumatoid arthritis, eosinophilic fasciitis, allergic angiitis, or sarcoidosis), skin diseases (e.g., pemphigus, dermatitis herpetiformis), another comorbid infection, or pancreatitis; contraindications for regarding endoscopic procedures; age of <18 years; pregnancy; malignant biliary tract diseases; and lack of informed consent.

The severity of the patients' cholangitis was classified as systemic inflammation, cholestasis, or imaging according to the Tokyo TG13 diagnostic criteria. ${ }^{13}$ All patients with cholangitis were hospitalized, and began hydration therapy and ceftriaxone ( $2 \mathrm{~g} /$ day) according to their underlying diseases. It was planned to modify the antibiotic treatment if required according to the patients' clinical conditions and blood culture results at the time of admission.

All patients underwent ERCP to ensure biliary drainage during the first 24 hours after admission. Cholangiography was performed using the smallest possible quantity of contrast after cannulation by papilla sphincterotomy during the ERCP procedure. Patients with cholangitis were followed up in terms of the need for repeated procedures and/or antibiotic modification during their hospitalisation. Patients who were hospitalized for at least three days were discharged with oral antibiotic therapy when their clinical and laboratory findings had normalised. We referred the patients with insitu gallbladder to the surgery clinic for cholecystectomy aimed to prevent further cholangitis attacks.

The CBC, biochemical parameters, prothrombin time, CRP level, and PCT level of all patients were measured prior to the procedure. These parameters were monitored daily in the patients with cholangitis, but were not measured daily in the control group because they were not hospitalised. Only CBC was measured in control group. Blood samples for the CBC examination were collected in tubes containing ethylenediaminetetraacetic acid. Cells were counted by an automatic analyser
(CELL DYN 3700). The reference range of the white blood cell count was determined as 4500 to $10,000 \mathrm{~K} / \mathrm{UL}$, while the detection limit of the eosinophil count was determined as 10 cells $/ \mathrm{mm}^{3}$. PCT prediction was carried out with time change-reinforced cryptate emission technology by measuring the signal sent by a time-lagged immunocomplex (MINIVIDAS; bioMérieux, Marcy-l'Étoile, France). CRP was measured with an immunoturbidimetric analyzer (BNII/BN ProSpec System; Siemens Healthineers, Erlangen, Germany).

The laboratory parameters of the patients in the study and control groups were compared prior to the ERCP. The daily white blood cell count, eosinophil count, CRP level and PCT level of the patients in the study group were measured. After the ERCPs, the changes in the values of these parameters in predicting a clinical response to treatment and the need for repeated ERCP was compared. Also we compared these parameters for predicting the clinical response and the need for repeated ERCP.

All statistical analyses were performed with SPSS version 15 software (SPSS Inc, Chicago, IL, USA). All results were indicated as frequencies, percentages, mean \pm S.D and median [IQR]. The Chi-square test was used to compare the categorical variables. The Kolmogorov-Smirnov test was used to determine whether the continuous data were normally distributed. All normally distributed data were analysed using Student's t-test, while the non-normally distributed data were analysed using the Mann-Whitney U-test and Kruskal-Wallis test. The continuous variables were compared in defined periods before and after ERCP was carried out using the Friedman test done with Post-hoc analysis for pair-wise comparisons. Statistical heterogeneity was quantified using Cochran's $Q$ test, $\tau^{2}$ and $I^{2}$ statistics. As it was applied and results in Table II were obtained by thistest. The receiver operating characteristic (ROC) curve analysis was used to identify the optimal cut-off values of the eosinophil count with maximum sensitivity and specificity to differentiate the cholangitis and control groups. The $p$-value of $<0.05$ was considered statistically significant.

\section{RESULTS}

A total of 77 patients were hospitalised in the Department of Gastroenterology, Sakarya Training and Research Hospital during the course of the study. Fifteen patients were excluded from the study for the following reasons of ECRP not implemented in the first 24 hours $(n=5)$, malignant appearing bile tract stenosis $(n=5)$, hypereosinophilia $(n=1)$, allergic asthma $(n=1)$, pregnancy $(n=1)$, hemolytic anemia $(n=1)$, and lack of consent $(n=1)$. The remaining 62 stone-related cholangitis patients were included in the study group. Fifty-seven patients with choledocholithiasis without signs of cholangitis were included in the control group to whom ERCP was applied.

The mean age in the study group was $67 \pm 14.57$ years, while it was $57.4 \pm 18.10$ years in the control group $(p=0.002)$. The gender distribution (female/male) was $26 / 36(41.9 \% / 48.1 \%$ ) in the study group and $39 / 18(68.4 \% / 31.6 \%)$ in the control group $(p=0.004)$. 
Table I: Omnibus tests of model coefficients and logistic regression analysis showing the effect of eosinophil threshold value in predicting the diagnosis of cholangitis.

\begin{tabular}{|c|c|c|c|c|}
\hline \multirow{2}{*}{$\begin{array}{l}\mathrm{p1}^{\mathrm{a}} \\
\text { Eosinophil threshold } \\
\text { Ref: Eos } \leq 100.5\end{array}$} & \multirow[b]{2}{*}{ Wald } & \multirow[b]{2}{*}{ Ratio } & \multicolumn{2}{|c|}{ 95\% confidence interval } \\
\hline & & & Lower & Upper \\
\hline Eos $>100.5$ & 28.902 & 12.487 & 4.974 & 31.349 \\
\hline Constant & 14.398 & 0.370 & & \\
\hline \multicolumn{5}{|c|}{$\begin{array}{l}\text { a. Variable(s) entered on step 1: Eosinophil threshold (cut off=100.5). } \\
\text { Omnibus Tests of Model Coefficients }\end{array}$} \\
\hline & & Chi-square & df & Sig. \\
\hline \multirow{3}{*}{ Step 1} & Step & 36,276 & 1 &, 000 \\
\hline & Block & 36,276 & 1 &, 000 \\
\hline & Model & 36,276 & 1 &, 000 \\
\hline
\end{tabular}

Table II: Recovery of eosinophil count, CRP level, and PCT level from baseline on the admission, first, third, and discharge (last) days of hospitalisation.

\begin{tabular}{|c|c|c|}
\hline Parameters & $\begin{array}{l}\text { Recovered according to basal } \\
\qquad(\%)\end{array}$ & $\begin{array}{c}\text { Recovered according to normal } \\
\text { reference range } \\
n(\%)\end{array}$ \\
\hline Eosinopenia admission day & $44(\% 71.0)$ & $25(\% 40.3)^{a}$ \\
\hline $1^{\text {st }}$ day & $55(\% 88.7)^{c}$ & $29(\% 46.8)^{\mathrm{a}}$ \\
\hline $3^{\text {rd }}$ day & $56(\% 90.3)$ & $36(\% 58.1)^{\mathrm{a}}$ \\
\hline Last visit & $56(\% 90.3)$ & $43(\% 69.4)^{a}$ \\
\hline C-reactive protein (CRP) admission day & $30(\% 48.4)$ & $1(\% 1.6)$ \\
\hline $1^{\text {st }}$ day & $44(\% 72.1)$ & $1(\% 1.6)$ \\
\hline $3^{\text {rd }}$ day & $48(\% 77.4)$ & $3(\% 4.8)$ \\
\hline Last visit & $49(\% 80.3)$ & $4(\% 6.5)$ \\
\hline Procalcitonin (PCT) admission day & $51(\% 82.3)^{b}$ & $1(\% 1.6)$ \\
\hline $1^{\text {st }}$ day & $56(\% 90.3)^{c}$ & $2(\% 3.2)$ \\
\hline $3^{\text {rd }}$ day & $58(\% 93.5)^{c}$ & $2(\% 3.2)$ \\
\hline Last visit & $56(\% 90.3)$ & $3(\% 4.8)$ \\
\hline
\end{tabular}

Table III. Median inflammatory markers of patients with cholangitis at applied, $\mathbf{1}^{\text {st }}, 3^{\text {rd }}$, and discharge (last) day.

\begin{tabular}{|c|c|c|c|}
\hline Parameters & Days & Median [IQR,Q1-Q3] & $\mathbf{p}$ \\
\hline \multirow{4}{*}{ WBC } & Admission & $12500[8680-16975]$ & \multirow{4}{*}{$<0.001$} \\
\hline & $1^{\text {st }}$ & $9265[7237.5-13900]$ & \\
\hline & $3^{\text {rd }}$ & $7800[5595.5-9425]$ & \\
\hline & Last & $7850[5875-9750]$ & \\
\hline \multirow{4}{*}{ EOS } & Admission & $25[10-52.25]$ & \multirow{4}{*}{$<0.001$} \\
\hline & $1^{\text {st }}$ & $70.7[24.75-150.5]$ & \\
\hline & $3^{\text {rd }}$ & $118.5[73.75-237.5]$ & \\
\hline & Last & $145.5[93.8-252.8]$ & \\
\hline \multirow{4}{*}{ CRP } & Admission & $101.4[56.8-155.5]$ & \multirow{4}{*}{$<0.001$} \\
\hline & $1^{\text {st }}$ & 110.5 [46.3-177] & \\
\hline & $3^{\text {rd }}$ & $54.80[23.8-92]$ & \\
\hline & Last & $47.95[16.5-83.9]$ & \\
\hline \multirow{4}{*}{ PCT } & Admission & $1.97[0.40-8.89]$ & \multirow{4}{*}{$<0.001$} \\
\hline & $1^{\text {st }}$ & $1.42[0.33-6.68]$ & \\
\hline & $3^{\text {rd }}$ & $0.63[0.20-2.19]$ & \\
\hline & Last & $0.55[0.25-1.74]$ & \\
\hline
\end{tabular}

Sixty-two patients in the cholangitis group underwent ERCP and sphincterotomy. ERCP was performed on all patients in the first 24 hours after admission. A nasobiliary drainage tube was placed in 11 patients during the ERCP procedure due to residual stones or sludge $(n=5)$, a large-volume stone that could not be extracted $(n=2)$ and a benign-appearing distal stricture $(n=4)$. Furthermore, a plastic stent was placed in 12 patients due to residue stones or sludge $(n=6)$, a large-volume stone that could not be extracted $(n=2)$, and a distal stricture $(n=4)$. 
Table IV: Inflammatory parameters before and after ERCP in patients with repeat ERCP.

\begin{tabular}{|c|c|c|c|c|c|c|c|}
\hline \multirow[b]{2}{*}{ Patients } & \multirow[b]{2}{*}{ Parameters } & \multicolumn{4}{|l|}{ First ERCP } & \multicolumn{2}{|l|}{ Repeated ERCP } \\
\hline & & $\begin{array}{l}\text { Pre procedure-applied } \\
\text { day }\end{array}$ & $\begin{array}{l}\text { Post } \\
\text { procedure 2nd } \\
\text { day }\end{array}$ & $\begin{array}{l}\text { Post } \\
\text { procedure 3rd } \\
\text { day }\end{array}$ & $\begin{array}{l}\text { Post } \\
\text { procedure 5th } \\
\text { day }\end{array}$ & Pre Procedure & $\begin{array}{l}\text { Post } \\
\text { procedure 3rd } \\
\text { day }\end{array}$ \\
\hline \multirow{3}{*}{$1^{\text {st }}$ patient } & $\operatorname{EOS}\left(10^{3} / \mathrm{uL}\right)$ & 10 & 37 & 30 & - & 30 & 102 \\
\hline & $\mathrm{CRP}(\mathrm{mg} / \mathrm{dl})$ & 245 & 315 & 242 & - & 242 & 87.8 \\
\hline & РCT(ng/ml) & 76.4 & 46.3 & 31.06 & - & 31.06 & 3.3 \\
\hline \multirow{3}{*}{$2^{\text {nd }}$ patient } & $\operatorname{EOS}\left(10^{3} / \mathrm{uL}\right)$ & 8 & 18 & 7 & 4 & 4 & 141 \\
\hline & $\mathrm{CRP}(\mathrm{mg} / \mathrm{dl})$ & 237 & 239 & 181 & 99 & 99 & 73.8 \\
\hline & РCT(ng/ml) & 12.9 & 5.95 & 3.070 & 1.078 & 1.078 & 1.093 \\
\hline
\end{tabular}

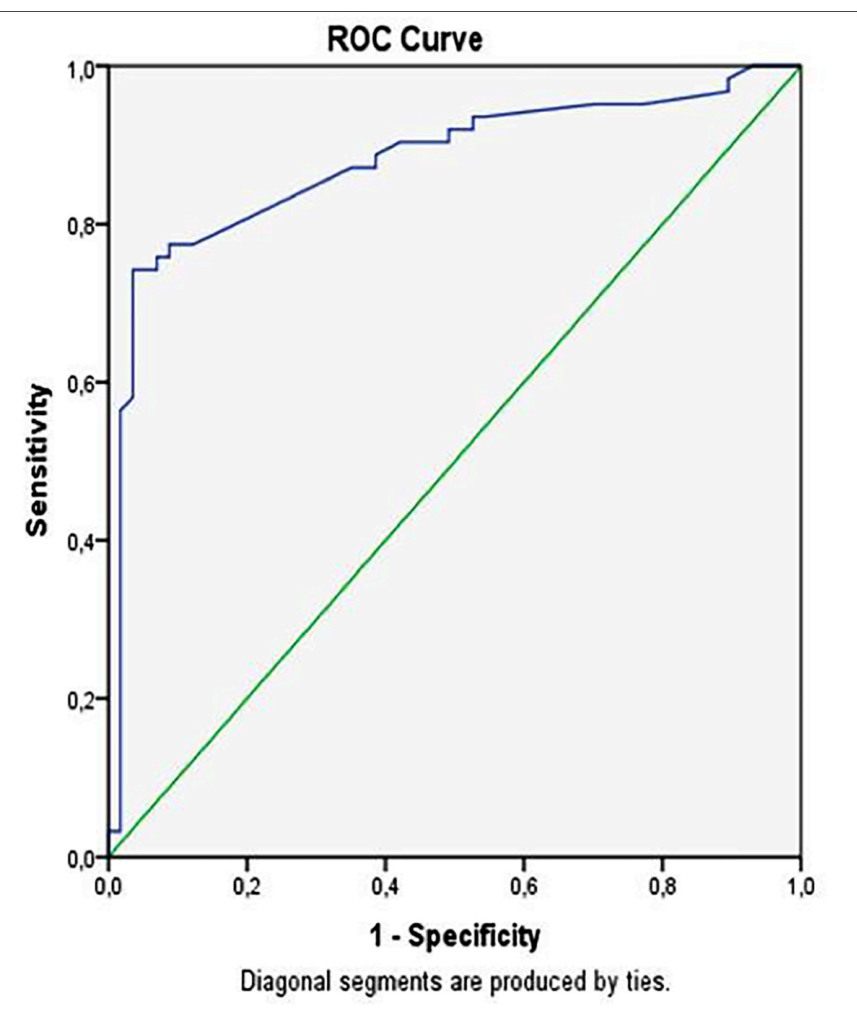

Figure 1: ROC curve for eosinophil count according to whether patients have cholangitis. AUC $=0.87(p<0.001)$.

The median eosinophil count was $17.50[9.82-84] \times 10^{3} / \mu \mathrm{L}$ in the cholangitis group at the time of admission and 168 $[100.11-270] \times 10^{3} / \mu \mathrm{L}$ in the control group $(\mathrm{P}<0.001)$. When cholangitis was classified according to severity, it was mild in 25 of the patients $(40.3 \%)$ and the median eosinophil count was 30.5 [10-100]; 27 (43.5\%) were moderate and the median eosinophil count was 16 [10-50]; 10 (16.1\%) were severe and the median eosinophil count was 10 [9.75-27] $(p=0.249)$.

The ROC curve analysis suggested that the optimum eosinophil count cut-off point for cholangitis was 100.5 cells/ $\mu \mathrm{L}$, with a sensitivity, specificity, positive predictive value, and negative predictive value of $87 \%, 65 \%, 72 \%$, and $81 \%$, respectively (area under the ROC curve, 0.877 , $p<0.001$, Figure 1). According to these findings, eosinopenia was present in 54(87.1\%) of the patients with cholangitis and $20(35.1 \%)$ of the patients in the control group when the limit of eosinopenia was defined as $<100.5$ cells $/ \mu \mathrm{L}(p<0.001)$. In the binary logistic regression of the dependent variables, which was performed to determine whether cholangitis was an independent predictive factor for eosinopenia $(<100.5$ cells/ $/ \mathrm{LL}$ ), the possibility of eosinopenia was 12.5 times higher in the patients with cholangitis than those without (Nagelkerke's $R^{2}, 35.1 \%$; odds ratio, $12.5 \mathrm{p}<0.001$, Table I).

Empirical ceftriaxone was initiated in all patients with cholangitis at a dosage of $2 \mathrm{~g} /$ day at the time of hospitalisation. During the follow-ups, a change in antibiotic therapy was required in 1 patient, while 61 patients completed their treatment with ceftriaxone. The patients were followed up for a mean of $3.5 \pm 0.9$ days after ERCP. When the course of eosinopenia was checked during the follow-ups, it was observed that the eosinophil count had reached a normal value by the first day in $71 \%$ of the patients, by the second day in $88.7 \%$ of the patients, by the third day in $90.3 \%$ of the patients, and by the last evaluation before discharge in $90.3 \%$ of the patients. The CRP levels were $48.4 \%, 72.1 \%$, $72.1 \%$, and $80.3 \%$, while the PCT levels were $82.3 \%, 90.3 \%$, $93.5 \%$, and $90.3 \%$, respectively. The recovery rate of the eosinophil count compared to the CRP on the first day was statistically significant $(88.7 \%$ vs $48.4 \%$ respectively, $p<0.001)$. The recovery rate according to the normal range was significantly high $(p<0.001)$ in patients with eosinopenia on the admission, first, third, and last days $(40.3 \%, 46.8 \%$, $58.1 \%$, and $69.4 \%$, respectively) compared with CRP $(1.6 \%$, $1.6 \%, 4.8 \%$, and $6.5 \%$, respectively) and PCT $(1.6 \%, 3.2 \%$, $3.2 \%$, and $4.8 \%$, respectively, Table II). Significantly higher than PCT $(82.3 \%)$, eosinopenia $(71.0 \%)$ and CRP $(48.4 \%)$ in showing improvement $(p<0.001$, Table II).

The median inflammatory markers of the patients on admission, 1st, 3rd, and discharge days are shown in Table III.

In the Friedman analysis of the inflammatory parameters, a significant difference was observed for each parameter at the specified times. In addition, pairwise comparisons were made using the Pairwise test. No significant difference was observed in WBC and CRP values between the third day and the day of discharge ( $p>0.999$, and $p=0.985$, respectively). Furthermore, while there was no significant difference between the admission day and the $1^{\text {st }}$ day in CRP, there was a significant difference in the paired comparison between other times ( $p=0.999$, and $p<0.001$ respectively). There was a significant difference in eosinophil values in the paired comparison between the admission day and 1-3-last days $(p=0.002, p<0.001, p<0.001$, respectively). The $p$-values for 
both comparison of 1st and 3rd, and 1st and last were significant ( $p=0.012$, and $p<0.001$, respectively). While there was no significant difference in PCT values between the $1^{\text {st }}$ day and the day of admission and the day of discharge (last), there was a significant difference in the pairwise comparisons between the other days ( $p>0.999, p=0.074, p<0.001$, respectively, Table III).

Cholangitic abscess was detected in one patient after ERCP. Enterococcus faecium isolated in the abscess culture taken was resistant to ceftriaxone. Pseudomonas aeruginosa grew in the blood culture taken from this patient. Ceftriaxone was discontinued, and piperacillin-tazobactam and vancomycin were initiated on the third day of his hospitalization. No improvement was observed in the CRP level, PCT level, or eosinophil count of this patient during the follow-ups. The patient died of secondary sepsis 11 days after ERCP. The eosinophil count was $30\left(10^{3} / \mu \mathrm{L}\right)$ before the 2 nd ERCP procedure in the 1st patient, and the eosinophil count on the 3rd day after the procedure was $102\left(10^{3} / \mu \mathrm{L}\right)$. CRP; It was 242 ( $\mathrm{mg} / \mathrm{dl}$ ) before the second ERCP procedure and 87.8 (mg / dl) on the 3rd day after the procedure. PCT; It was 31.06 (ng / $\mathrm{ml}$ ) before the procedure and 3.3 ( $\mathrm{ng} / \mathrm{ml}$ ) after the procedure. In patient 2 , the eosinophil count was $4(103 / \mu \mathrm{L})$ before the second ERCP procedure and $141\left(10^{3} / \mu \mathrm{L}\right)$ on the 3rd day after the procedure. CRP; It was 99 ( $\mathrm{mg} / \mathrm{dl}$ ) before the second ERCP procedure and $73.8(\mathrm{mg} / \mathrm{dl}$ ) on the 3rd day after the procedure. PCT; It was 1.078 ( $\mathrm{ng} / \mathrm{ml}$ ) before treatment and 1.093 (ng / ml) after treatment (Table IV).

\section{DISCUSSION}

In the present study, the eosinophil count of the patients with cholangitis was significantly lower than those without and significantly decreased as the severity of cholangitis increased $(P=0.046)$. Biomarkers used to detect and monitor the severity of infection; It should have high specificity and sensitivity, be fast, inexpensive, and correlate with the severity and prognosis of the disease. Such markers are clinically significant in terms of infection follow-up and possible changes in antibiotic therapy, especially in patients undergoing intensive care. White blood cell count, CRP level and PCT level are routinely used biomarkers.

Eosinopenia is a form of agranulocytosis in which the number of eosinophils is lower than expected. It is argued that eosinopenia may occur by the immigration of chemotactic factors such as $\mathrm{C} 5 \mathrm{a}$ to an area of acute inflammation according to oscillations in the quantity of eosinophils. ${ }^{14}$ Moreover, it is also considered that the stress- and inflammation-induced release of mediators affects the bone marrow suppression. ${ }^{15}$ The literature contains no precise cut-off value with which to define eosinopenia as different researchers have reported values ranging from $<40$ cells $/ \mathrm{mm}^{3}$ to $<50$ cells $/ \mathrm{mm}^{3,16,17}$ On the other hand, some researchers have argued that eosinopenia should be defined as an eosinophil count of $<1 \%$ of the total leukocytes, implying that eosinopenia should be defined by a value of $<100$ cells $/ \mathrm{mm}^{3,18}$ The eosinophil count in patients hospitalized in the intensive care unit in survivors [30 cells / $\mathrm{mm}^{3}$; (IQR), 0-100 cells / $\mathrm{mm}^{3}$ ] and non-survivors ( 0 cells / mm $\mathrm{mm}^{3}$; IQR, 0-30 cells / $\mathrm{mm}^{3} ; \mathrm{p}=0.004$ ) is significant different was found. ${ }^{10}$ Absolute eosinophil counts remained significantly lower from admission to the seventh day in non-survivors. ${ }^{10}$ Eosinopenia has the advantage of not requiring further investigations because it can be easily obtained from a simple CBC. Furthermore, one study revealed that patients who had eosinopenia and received effective antimicrobial therapy during bacterial infection recovered from eosinopenia within 24 hours. This period of time was earlier than the granulocyte count, CRP level, and fever, which began to normalize after 3 days. ${ }^{18}$

More recently, a study performed in an emergency department demonstrated that profound eosinopenia is very specific to sepsis and may become a helpful tool in daily practice. ${ }^{19}$

The CRP level begins to increase 4 to 6 hours after the beginning of inflammation and reaches its peak value after 24 to 48 hours. ${ }^{20}$ The CRP level remains high as long as inflammation and tissue damage continue, and returns to normal in 3 to 7 days when the inflammation ends as its half-life ranges from 4 to 7 hours. $^{21}$

PCT is a serum biomarker that increases in response to bacterial infection. Several studies carried out during the last few decades have reported that CRP, and more recently PCT, are not specific for sepsis but are rather markers of systemic inflammatory response syndrome, as defined previously at a consensus conference for sepsis. ${ }^{22,23}$

The main limitations of the present study were its relatively small number of patients and the fact that it was a single-center design. In addition, the study was conducted at a gastroenterology reference centre. The strengths of this study were its cross sectional and no randomisation design and the fact that is the first study conducted to evaluate eosinopenia in response to cholangitis treatment.

Prospective studies involving larger number of patients are needed for these findings to become valuable.

\section{CONCLUSION}

Eosinopenia can be used as an inflammatory marker that can be detected at the first visit of patients with cholangitis. It is a fast, easy and inexpensive method compared to CRP and PCT in predicting the clinical course of patients.

\section{ETHICAL APPROVAL:}

The study protocol was approved by the Ethics Committee (Registration No: 16214662/050.01.04/7).

\section{PATIENTS' CONSENT:}

Written informed consents were obtained from all patients or their legal representatives.

\section{CONFLICT OF INTEREST:}

The authors declare no conflict of interest. 


\section{AUTHORS' CONTRIBUTION:}

CK: Data collection, compiling, statistics and discussion.

ATE: Contributed to design articles and analysing data.

BT: Contributed to collecting and analysing data.

MT: Contributed to collecting data.

EP: Helped perform the analyses with constructive discussions.

ASK: Led and conceived the project, and authored the manuscript.

\section{REFERENCES}

1. Boey JH, Way LW. Acute cholangitis. Ann Surg 1980; 191(3):264-70. doi:10.1097/00000658-198003000-00002.

2. Sung JY, Costerton JW, Shaffer EA. Defense system in the biliary tract against bacterial infection. Dig Dis Sci 1992; 37(5):689-96. doi:10.1007/bf01296423.

3. Mosler P. Diagnosis and management of acute cholangitis. Curr Gastroenterol Rep 2011; 13(2):166-72. doi:10.1007/s11894-010-0171-7.

4. Salek J, Livote E, Sideridis K, Bank S. Analysis of risk factors predictive of early mortality and urgent ERCP in acute cholangitis. J Clin Gastroenterol 2009; 43(2):171-175. doi:10.1097/MCG.0b013e318157c62c.

5. Anciaux ML, Pelletier G, Attali P, Meduri B, Liguory C, Etienne JP. Prospective study of clinical and biochemical features of symptomatic choledocholithiasis. Dig Dis Sci 1986; 31(5):449-453. doi:10.1007/bf01320306.

6. Barnes PJ. Inflammatory mechanisms in patients with chronic obstructive pulmonary disease. J Allergy Clin Immunol 2016; 138(1):16-27. doi:10.1016/j.jaci.2016. 05.011

7. Moyer MW. New biomarkers sought for improving sepsis management and care. Nat Med 2012; 18(7):999. doi:10. 1038/nm0712-999.

8. Bass DA. Behavior of eosinophil leukocytes in acute inflammation. I. Lack of dependence on adrenal function. J Clin Invest 1975; 55(6):1229-36. doi:10.1172/JCl108041

9. Anand D, Das S, Bhargava S. Procalcitonin as a rapid diagnostic biomarker to differentiate between culture-negative bacterial sepsis and systemic inflammatory response syndrome: a prospective, observational, cohort study. J Crit Care 2015; 30(1): doi:10.1016/j.jcrc.2014.08.017

10. Abidi K, Belayachi J, Derras Y, Khayari ME, Dendane T, Madani $\mathrm{N}$, et al. Eosinopenia, an early marker of increased mortality in critically ill medical patients. Intensive Care Med 2011; 37(7):1136-42. doi:10.1007/s00134-011-2170-z

11. Garnacho-Montero J, Huici-Moreno MJ, Gutiérrez-Pizarraya A, López I, Márquez-Vácaro JA, Macher $\mathrm{H}$, et al. Prognostic and diagnostic value of eosinopenia, C-reactive protein, procalcitonin, and circulating cell-free DNA in critically ill patients admitted with suspicion of sepsis. Crit Care 2014; 18(3):R116. doi:10.1186/cc13908.

12. Sur S (Eosinophils. Biochemical and cellular aspects. In:
Allergy: Principles and Practices. 1993. p. 169-200.

13. Kiriyama S, Takada T, Strasberg SM, Solomkin JS, Mayumi, Pitt HA, et al. New diagnostic criteria and severity assessment of acute cholangitis in revised Tokyo Guidelines. J Hepatobiliary Pancreat Sci. 2012; 19(5):548-56. doi:10. 1007/s00534-012-0537-3

14. Zeck-Kapp G, Kroegel C, Riede UN, Kapp A. Mechanisms of human eosinophil activation by complement protein $\mathrm{C} 5 \mathrm{a}$ and platelet-activating factor: similar functional responses are accompanied by different morphologic alterations. Allergy 1995; 50(1):34-47. doi.org/10.1111/ j.1398-9995.1995.tb02481.x.

15. Ramirez GA, Yacoub MR, Ripa M, Mannina D. Cariddil A, Saporiti N, et al. Eosinophils from Physiology to Disease: A Comprehensive Review. BioMed research international 2018; 9095275. doi.org/10.1155/2018/9095275.

16. Gil H, Magy N, Mauny F, Dupond JL. Valeur de l'éosinopénie dans le diagnostic des syndromes inflammatoires: Un "vieux" marqueur revisité [Value of eosinopenia in inflammatory disorders: an "old" marker revisited]. Rev Med Interne 2003; 24(7):431-5. doi:10.1016/s0248-8663(03)00138-3.

17. Abidi K, Khoudri I, Belayachi J, Madani N, Madani N, Zekraoui A, et al. Eosinopenia is a reliable marker of sepsis on admission to medical intensive care units. Crit Care 2008; 12(2): R59. doi:10.1186/cc6883.

18. Davido B, Makhloufi S, Matt M, Calin R, Senard $O$, Perronne $C$, et al. Changes in eosinophil count during bacterial infection: revisiting an old marker to assess the efficacy of antimicrobial therapy. Int J Infect Dis 2017; 61:62-6. doi:10.1016/ j.ijid.2017.06.005.

19. Lavoignet CE, Le Borgne P, Slimani H, Forato M, Kam C, Kauffmann $\mathrm{P}$, et al. Intérêt de l'éosinopénie dans le diagnostic de sepsis aux urgences [Relevance of eosinopenia as marker of sepsis in the Emergency Department]. Rev Med Interne 2016; 37(11):730-4. doi:10.1016/j.revmed. 2016.02.018.

20. Steel DM, Whitehead AS. The major acute phase reactants: $\mathrm{C}$-reactive protein, serum amyloid $\mathrm{P}$ component and serum amyloid A protein. Immunol Today 1994; 15(2):81-8. doi:10.1016/0167-5699(94)90138-4.

21. Jaye DL, Waites KB. Clinical applications of C-reactive protein in pediatrics. Pediatr Infect Dis J 1997; 16(8): 735-747. doi:10.1097/00006454-199708000-00003.

22. Le Bel J, Hausfater P, Chenevier-Gobeaux C, Blanc FX, Benjoar M, Ficko C, et al. Diagnostic accuracy of C-reactive protein and procalcitonin in suspected community-acquired pneumonia adults visiting emergency department and having a systematic thoracic CT scan. Crit Care 2015; 19:366. doi:10.1186/s13054-015-1083-6.

23. Chandy SJ, Naik GS, Charles R, Jeyaseelan V, Naumova EN, Thomas K, et al. The impact of policy guidelines on hospital antibiotic use over a decade: a segmented time series analysis. PLoS One 2014; 9(3):e92206. doi:10.1371/journal.pone. 0092206. 